\title{
DINÂMICA DAS EXPORTAÇÕES NO ESTADO DE MINAS GERAIS: UMA ANÁLISE DE SHIFT-SHARE (2008-2020)
}

Rosa Livia Gonçalves Montenegro' ${ }^{1}$ Sávio Augusto Tavares Costa ${ }^{2}$

Resumo: O presente trabalho teve como objetivo analisar as exportações das mesorregiões de Minas Gerais entre os anos 2008, 2012, 2016 e 2020, no qual foi comparado e analisado a evolução dos resultados das mesorregiões. A análise fornece um diagnóstico da situação das mesorregiões mineiras em relação às exportações dos principais itens que compõe a sua pauta. A análise foi feita utilizando o método shift-share, com base nos dados fornecidos pela Secretária do Comércio Exterior. Os resultados mostraram que a economia mineira experimentou a reprimarização na sua pauta exportadora. Ademais, os rompimentos das barragens de Mariana e Brumadinho e a crise provocada pela pandemia do COVID19 influenciaram a dinâmica do setor mínero-metalúrgico, considerado um dos principais na pauta de exportações em Minas Gerais.

Palavras-chave: Exportação. Minas Gerais. Shift-share. Mesorregiões.

\section{DYNAMICS OF EXPORTS IN THE STATE OF MINAS GERAIS: A SHIFT-SHARE ANALYSIS (2006 and 2016)}

Abstract: The present work aimed to analyze the exports of the mesoregions of Minas Gerais between the years 2008, 2012, 2016 and 2020, in which the evolution of the results of the mesoregions was compared and analyzed. The analysis provides a diagnosis of the situation of the mining mesoregions about to exports of the main items that set their agenda. The analysis was done using the shift-share method, based on data provided by the Secretary of Foreign Trade. The results showed that the mining economy experienced a reprimarization in its export basket. Furthermore, the disruptions of the Mariana and Brumadinho dams and the crisis caused by the COVID-19 pandemic influenced the dynamics of the mining and metallurgical sector, considered one of the main exports in Minas Gerais.

Keywords: Export. Minas Gerais. Shift-share. Mesoregions.

\section{DINÁMICA DE LAS EXPORTACIONES EN EL ESTADO DE MINAS GERAIS: UNA ANÁLISIS DE SHIFT-SHARE (2006 y 2016)}

Resumen: El presente trabajo tuvo como objetivo analizar las exportaciones de las mesorregiones de Minas Gerais entre los años 2008, 2012, 2016 y 2020, en el que se comparó y analizó la evolución de los resultados de las mesorregiones. El análisis brinda un diagnóstico de la situación de las mesorregiones mineras en torno a las

\footnotetext{
${ }^{1}$ Universidade Federal de Juiz de Fora, Programa de Pós-graduação em Economia Aplicada, Juiz de Fora, Brasil, rosa.livia@ufjf.br, https://orcid.org/0000-0001-8383-5131

2 Economista pela Universidade Federal de São João del Rei (UFSJ), saviocosta41@gmail.com, https://orcid.org/0000-0001-5215-494X
} 
exportaciones de los principales rubros que marcan su agenda. El análisis se realizó mediante el método shift-share, con base en datos proporcionados por la Secretaría de Comercio Exterior. Los resultados mostraron que la economía minera experimentó una reprimarización en su canasta exportadora. Además, las interrupciones de las represas Mariana y Brumadinho y la crisis provocada por la pandemia COVID-19 influyeron en la dinámica del sector minero y metalúrgico, considerado una de las principales exportaciones de Minas Gerais.

Palabras clave: Exportación. Minas Gerais. Shift-share. Mesorregiones.

\section{Introdução}

A reforma econômica no Brasil, iniciada há mais de uma década, levou a regimes de comércio e investimento mais globalizados, e produziu um ambiente descentralizado e mais orientado para o mercado externo. Neste contexto, o comércio internacional possibilitou ao País o aumento do consumo de bens e serviços que antes não eram produzidos internamente, seja por falta de matéria prima ou tecnologia e o desenvolvimento da economia local. Sob essa perspectiva, os governos têm proporcionado alguns estímulos às empresas (RUIZ, 2007). A exportação, nesse caso, pode ser o diferencial competitivo para as empresas, mesmo que esta represente um desafio. As empresas nacionais, no caso, não se manteriam limitadas à comercialização no mercado doméstico, podendo ampliar suas possibilidades de crescimento. De acordo com Araújo e Sartori (2004), os mecanismos competentes, por parte do governo, têm influência direta no desenvolvimento das exportações, incentivando fortemente as empresas nacionais a se ajustarem às exigências do mercado internacional, promovendo ainda mais as exportações e incentivando o setor exportador a se adequar e se apresentar de maneira competitiva.

Entretanto, o Brasil ainda não pode ser considerado um país exportador no nível de sua capacidade produtiva, devido às dificuldades que as empresas encontram no processo de exportação, pois ainda há obstáculos que impossibilitam melhorar seus índices de exportações (ROCHA, 2002). Os entraves podem ser, por exemplo, os tributários, alfandegários, logística de transporte e a taxa de câmbio, que foi apontada como o principal obstáculo para o crescimento das exportações.

Para minimizar um dos problemas, como a carga tributária, por exemplo, e incentivar as exportações, o governo brasileiro oferece, atualmente, alguns incentivos fiscais à atividade, criando regimes especiais direcionados, principalmente, às médias e pequenas empresas (RUIZ, 2007). O objetivo principal é 
a redução de encargos com a operação de exportação, suspendendo e/ou, até mesmo, isentando as empresas beneficiárias do pagamento de determinados impostos. Existem diversos métodos que podem ser adotados pelo governo para incentivar a exportação e a competitividade internacional, dentre os quais se pode citar o Drawback, que possibilita às empresas nacionais a exoneração dos tributos já citados, representando incentivo para a redução de custos das empresas nacionais (SOUZA e VIEIRA, 2016).

Como destaque das exportações, a mineração é uma das principais atividades econômicas do Brasil, sendo responsável por quase 5\% do Produto Interno Bruto (PIB). Além disso, sua diversidade de produtos é aplicada em atividades metalúrgicas, em áreas relacionadas a fertilizantes, siderúrgicas e petroquímicas (DNPM, 2016). Essa atividade é uma fonte de renda que equilibra os índices de crescimento do país, tendo em vista que a extração de recursos minerais expressivos, que abrangem uma produção de 72 substâncias minerais, das quais 23 são metálicas, 45 não-metálicas e quatro energéticas (SOUZA e VIEIRA, 2016).

Ressalta-se que de todos os estados brasileiros, o estado de Minas Gerais tem grande similaridade com o Brasil em relação à sua pauta de exportações, tendo em vista que é um Estado muito rico em recursos naturais, como commodities agrícolas e minerais, incluindo-se produtos de baixo valor agregado (IBRAM, 2015). Aliado a esses fatores, a formação histórica e econômica do Estado de Minas Gerais foi alicerçada em uma base rica de recursos naturais e sob uma integração interregional. Tal fato, consolidou o Estado como industrializado e exportador, desde a década de 1990, e convergiu com a estabilização monetária e abertura comercial. O Estado de Minas Gerais, portanto, apresentou uma posição de destaque no conjunto das Unidades Federativas. A relativa importância das exportações mineiras no total do país tem-lhe assegurado o posto de segundo principal Estado exportador da região Sudeste (DÓREA et al., 2015).

Logo, para a construção deste trabalho que analisa a importância da pauta exportadora de Minas Gerais, foram selecionados dezesseis dos noventa e nove capítulos, doravante denominados de setores, que possuem maior representatividade, de acordo com a Secretária do Comércio Exterior (SECEX), para as doze mesorregiões mineiras que mais exportaram entre 2008 e 2020. Definiu-se como recorte temporal os anos de 2008, 2012, 2016 e 2020, com intuito de apresentar as variações que aconteceram no intervalo temporal de doze anos. 
Procurou-se, também, apresentar um quadro das exportações entre esse intervalo temporal, das mesorregiões mineiras, e seus respectivos setores de maior relevância.

Os critérios de análise dos resultados envolvem verificar os setores que apresentaram, nos anos do período considerado, Vantagens Comparativas Reveladas (VCRs) elevadas, chamados setores com especialização permanente. Também procurou-se identificar os setores que perderam, ou seja, deixaram de ser especializados, ou ganharam especialização, no decorrer do período e, por último, os setores que apresentaram VCRs elevadas, em algum ano do período, chamados de "surtos" de especialização. A análise destes níveis de hierarquização tem como único propósito auxiliar na constatação do que se modificou (se é que modificou), na inserção externa do Estado de Minas Gerais, no período sob análise.

Logo, além da introdução, o trabalho está organizado em mais quatro seções. Na seção 2, será tratado a importância da pauta das exportações de Minas Gerais. No item seguinte, serão discutidas a metodologia e a base de dados. Na quarta seção serão detalhados os resultados. Por fim, na seção 5 , será tecida a conclusão do trabalho, salientando as contribuições e os principais resultados sob o efeito da metodologia aplicada ao período analisado.

\section{Conjuntura econômica brasileira no período 2008 a 2020: um breve resumo sobre o contexto das exportações}

As exportações brasileiras para o período em análise tiveram diferentes reações sob os cenários de recessão e recuperação econômica, tanto a nível nacional quanto internacional. Um dos fatores que causaram a desestabilidade sobre a atividade do comércio exterior do país, referiram-se às incertezas do mercado de commodities e as medidas protecionistas que vem ocorrendo nos últimos anos, por intermédio de barreiras não tarifárias. Em síntese, serão relatados neste item os fatos mais importantes e que foram destaques nos anos analisados no trabalho. Os anos escolhidos podem ser justificados pelas ocorrências de tais fatos e, ajudam a analisar de forma escalonada a evolução e o comportamento das exportações em Minas Gerais.

Para o ano de 2008, é necessário compreender o contexto do período anterior, isto é, a partir do ano de 2007, observou-se um movimento no qual as importações aumentaram, em decorrência do seu câmbio apreciado e, as 
exportações mantiveram seu crescimento. Alguns fatores podem ser elencados para configurar esse cenário, como o aumento da demanda interna e a renda per capita brasileira que se mantiveram em um patamar mais sustentável (SALVATO, SANT'ANNA E SILVA, 2008). Posteriormente, com a crise mundial de 2008 marcada pela desestabilidade da economia norte-americana e, ao mesmo tempo, com as exportações de commodities brasileiras em alta, o País manteve o superávit na balança comercial com câmbio valorizado. Com esse resultado, é possível identificar o processo de reprimarização da pauta exportadora brasileira, no qual amplia a base para a venda de produtos primários no mercado internacional (MEYER e PAULA, 2009).

Após esse resultado na pauta das exportações brasileiras, o período que antecede o ano de 2012, também foi marcado pela influência no preço das commodities, sendo influenciada pelo avanço dos mercados emergentes, especialmente dos países asiáticos, nos quais a demanda pelos produtos primários movimento o preço das commodities nesse período. Logo, o valor mais elevado das commodities estaria incitando uma especialização da pauta exportadora na condução destes produtos e, por sua vez, manteve a taxa de câmbio real corrente em um patamar inferior para garantir a receita das exportações. Contudo, com a taxa de câmbio real em níveis baixos, os produtos de maior valor agregado, assim como as exportações de bens manufaturados intensivos em tecnologia pesam sobre a menor participação da indústria brasileira no cômputo das exportações (BRESSER-PEREIRA, 2018).

Quanto ao ano de 2016, o Brasil vivia a incerteza da estabilização dos preços das commodities agrícolas, momento pelo qual o governo esperava um crescimento das exportações. No período, a rentabilidade das exportações brasileiras diminuiu em 8,2\% (FUNCEX, 2020). Houve o aumento do custo de produção das empresas, atrelado à diminuição de $6,2 \%$ dos preços dos produtos exportados, mesmo com a desvalorização do real. Ademais, com a desvalorização das commodities, o baixo ritmo da dinâmica do comércio internacional no período, impulsionou os preços de produtos manufaturados. Observou-se, portanto, um fôlego da indústria nacional que aproveitou a vantagem do câmbio favorável para adquirir mais espaço em mercados externos. Como resultado, a indústria de transformação aumentou suas exportações em $1,2 \%$ (FUNCEX, 2020). 
Por fim, o ano de 2020 foi marcado por um conjunto de fatores que impactou não somente a economia brasileira, mas a economia global. $O$ fator mais marcante foi a pandemia da Covid-19, em que ocasionou a maior crise da economia mundial desde a Grande Depressão de 1930. Especificamente para as exportações brasileiras, o cenário de incertezas no âmbito internacional dificultou e contribuiu para que a atividade econômica nacional sentisse os efeitos da crise, como por exemplo: a diminuição da renda, o endividamento das famílias e empresas e uma baixa demanda por bens de consumo duráveis e semiduráveis. As exportações commodities agrícolas e alimentares tiveram uma queda menos acentuada em virtude da demanda de alimentos por países asiáticos como a China (RIBEIRO et al., 2020). Contudo, observou-se que as exportações de minério de ferro e de petróleo diminuíram com a redução da demanda e dos preços, restringindo ainda mais a pauta exportadora brasileira em commodities.

Desse modo, o objetivo da análise escalonada entre os anos de 2008 a 2020, será investigar a pauta exportadora de Minas Gerais, paralelamente ao comportamento da economia brasileira no período, descrito no presente item. Ademais, além das características distintas das exportações brasileiras entre os anos analisados, outros elementos influenciaram especificamente as exportações em Minais Gerais, sob período em estudo. A questão dos rompimentos das barragens em Mariana, no ano de 2015 e, em Brumadinho no ano de 2019, foi um exemplo destes fatores que impactaram a pauta exportadora, como será observado nos resultados referentes a esse período.

\section{A importância da pauta exportadora da mineração: uma análise para minas gerais (2008 - 2020)}

Sob o contexto histórico de Minas Gerais, ressalta-se que o estado sempre foi destaque do setor da mineração, considerado também como um setor de força motriz de desenvolvimento (NAHAS et al., 2019). A atividade mineradora iniciou-se aproximadamente na década de 1680, período em que foi descoberto o ouro em Vila Rica, hoje conhecido como a microrregião de Ouro Preto e, na região onde atravessa o Rio das Velhas, em que atualmente representa a região metropolitana de Belo Horizonte (NAHAS, 2010).

De acordo com Diniz (1981), apesar da economia mineira baseada na agropecuária e na indústria alimentícia, na década de 1900, sua transformação em direção ao setor extrativo mineral ocorreu entre as décadas de 1920 e 1930. No 
período supracitado, o estado de Minas Gerais já detinha posição de destaque nacional na metalurgia. A Companhia Siderúrgica Belgo-Mineira, antiga Companhia Siderúrgica Mineira, foi um dos exemplos que consolidou o estado no campo siderúrgico nacional.

Entre as décadas de 1940 e 1960, foi constituída a Companhia Vale do Rio Doce e sua liberalização ao capital estrangeiro, além de outras empresas do setor extrativo mineral, entre elas: Minerações Brasileiras Reunidas (MBR), Samitri, Ferteco, Alcoa, Usiminas, entre outras (VAL, VIANA e MARTINS, 2012 e NAHAS et. al., 2019)). A partir da década de 1970, apesar da expansão do setor em função do aumento da demanda interna, houve significativa perda da participação do setor mineral, com relação a economia brasileira e mineira (NAHAS et al., 2019).

Em resumo, Minas Gerais foi alicerçado sobre uma base rica de recursos naturais e sob uma integração inter-regional, que o consolidou como estado industrializado e exportador, desde a década de 1990, com a estabilização monetária e abertura comercial - o Estado de Minas Gerais apresentou uma posição de destaque no conjunto das Unidades Federativas. A relativa importância das exportações mineiras no total do país tem-lhe assegurado o posto de segundo principal Estado exportador da região Sudeste. No ano de 2016 exportou US\$ 17,826 bilhões $(11,64 \%$ do valor total), e obteve um saldo comercial de US\$1,47 bilhão, com o cômputo de minério de ferro sendo o produto mais exportado (TORRES, PALERMO e PORTUGAL, 2013).

Atualmente, o estado de Minas Gerais ocupa posição de destaque neste setor, extraindo mais de 160 milhões de toneladas/ano de minério de ferro (IBRAM, 2015). Além disso, é responsável por aproximadamente $53 \%$ da produção brasileira de minerais metálicos e $29 \%$ de minérios em geral (IBRAM, 2015). As reservas mineiras de nióbio possuem estoque para mais de 400 anos e, existem somente três minas em todo o mundo (IBRAM, 2015). A atividade de mineração está presente em mais de 250 municípios mineiros.

Entre os dez maiores municípios brasileiros mineradores, sete estão em Minas, sendo Itabira o maior do País; com mais de 300 minas em operação (IBRAM, 2015). Das 100 maiores minas do Brasil, 40 estão localizadas no Estado e, 67\% das minas classe A (produção superior a três milhões t/ano) estão em Minas Gerais. A evolução da Produção Mineral Brasileira (PMB) demonstra o quanto o Brasil já avançou no crescimento e diversificação da exploração de seus recursos minerais. 
Em 2014, foram US\$ 40 bilhões, e em 2015, o valor estimado foi de US\$ 38 bilhões (IBRAM, 2015).

No âmbito nacional, observa-se mudanças na indústria extrativista mineral desde os anos 2000, tendo em vista a forte demanda da China por minérios. Como especificado, Minas Gerais (Figura 1) possui a maior produção de minério de ferro, ouro, zinco, fosfato e nióbio, sendo este último também a maior do mundo (92\%); e o 2ำ maior produção de bauxita; 3ํ maior em produção de níquel e, tem a maior reserva de manganês. No período entre os anos de 2011 a 2013, Minas Gerais ocupou o 1ำ lugar em arrecadação da CFEM (Compensação Financeira pela Exploração de Recursos Minerais), num total de 51,07\%, 53,18\% e 50, 74\% respectivamente.

Figura 1- Mesorregiões de Minas Gerais

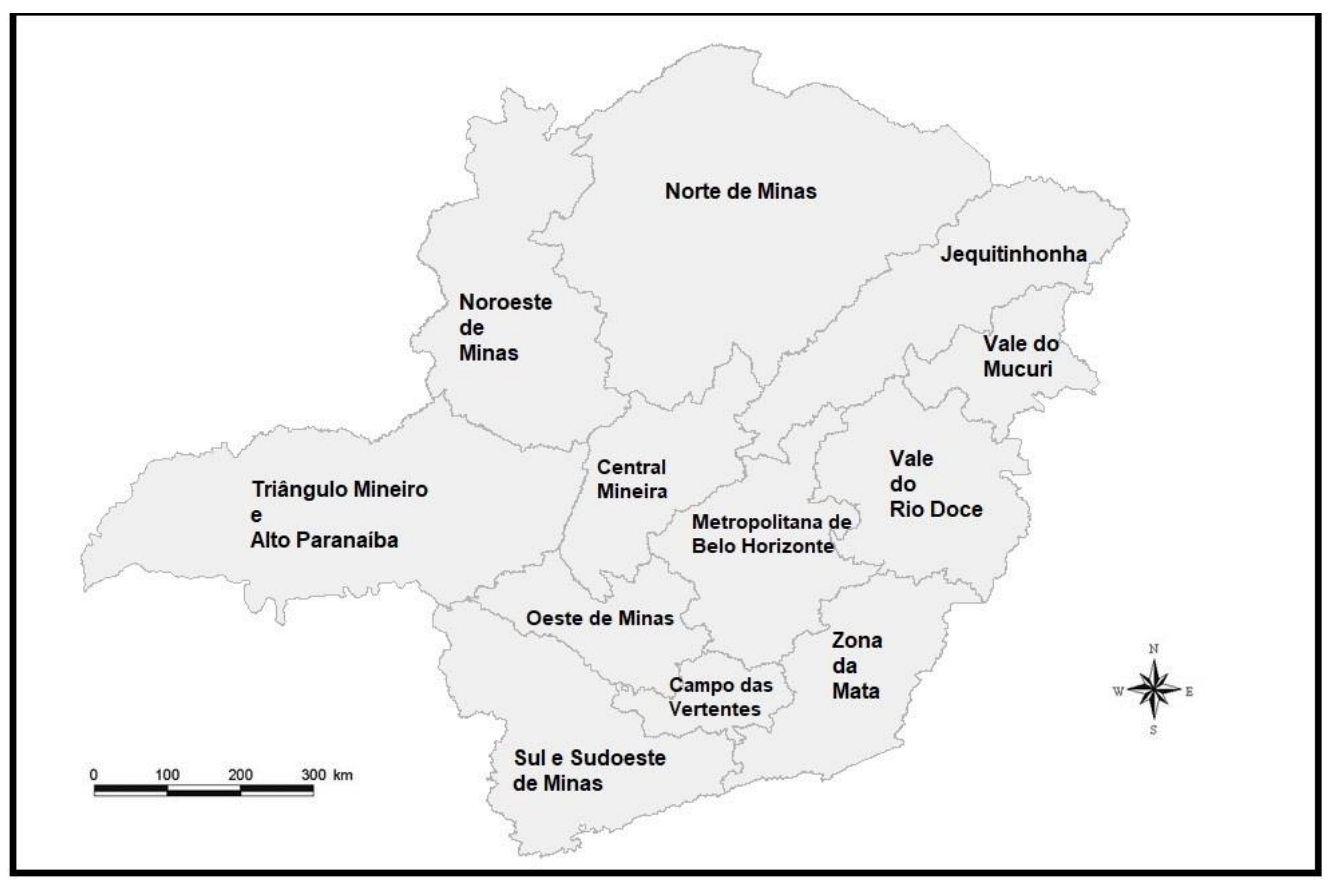

Fonte: Elaboração própria dos autores.

De acordo com a Secretária do Comércio Exterior (SECEX), do Ministério do Desenvolvimento, da Indústria e do Comércio Exterior, no ano de 2014, o minério de ferro permaneceu liderando, mais uma vez, a pauta de exportações na conta de produtos básicos, sendo o insumo responsável por $11,47 \%$ dos produtos básicos. Mesmo com uma variação no preço em 2014 , em torno de $(-20,54 \%)$, o minério de ferro permaneceu liderando este segmento, sendo que, sua produção no país foi da ordem de 400 milhões de toneladas, e sua exportação foi responsável pelo aporte de US\$25,8 bilhões na balança comercial brasileira (SECEX, 2014). Vale ressaltar 
que o Brasil é o segundo maior exportador mundial do produto, atrás apenas da Austrália (IBRAM, 2015).

A pauta de exportações das micro e pequenas empresas (MPEs) brasileiras é considerada bastante diversificada em termos de produtos. As MPEs constituem 61,6\% das empresas que exportam no Brasil. Em um amplo estudo feito pelo Sebrae (Serviço Brasileiro de Apoio às Empresas) e pela Fundação Centro de Estudos do Comércio Exterior (Funcex) sobre as MPEs exportadoras - de 1998 a 2010 - apontou-se que 11.858 delas exportaram em 2010 pouco mais de US\$ 2 bilhões, o que representa um aumento de 7,6\% no valor das exportações em comparação a 2009. Na média, cada MPE exportou US\$ 170,9 mil (ENERGIA, 2014)

Para analisar a evolução e as mudanças dos dezesseis setores, especialmente em relação ao setor extrativo mineral, será aplicada a metodologia de shift-share de acordo com os anos sob estudo. A seguir, será descrito a metodologia e a base de dados utilizada na análise.

\section{Metodologia e base de dados}

\section{Base dados e tratamento das variáveis}

O presente item propõe a análise da evolução do padrão das exportações do Estado de Minas Gerais no período entre os anos 2008 e 2020, por meio da construção de indicadores que medem o grau de competitividade dos setores produtivos. Os indicadores mostram o dinamismo exportador da economia de Minas Gerais apontando os setores produtivos que apresentam maior/menor competitividade e especialização no período em questão. A partir disso, é possível destacar o grau de concentração da pauta de exportação mineira mostrando se a pauta é diversificada e qual a composição da pauta de exportações.

Os indicadores são baseados nos fluxos comerciais e base de dados fornecidos pela Secretaria do Comércio Exterior (SECEX) do Ministério do Desenvolvimento, Indústria e Comércio do Brasil (MDIC), disponível por meio do Sistema de Análise das Informações do Comércio Exterior (ALICE). Para o estudo realizado neste trabalho, utilizou-se como referência a Nomenclatura Comum do Mercosul (NCM), adotada pelo Ministério do Comércio Exterior como modelo de classificação e agrupamento de dados em relação à importação e exportação nacionais. A NCM classifica os produtos exportados e importados em 99 setores. 
Os dados no site AliceWeb, que trata das exportações brasileiras, são divididos em 99 setores, limitando cada tipo de exportação a uma vertente. Posteriormente a coleta das informações dos 99 setores, foram selecionados dezesseis setores ${ }^{3}$ com maior representatividade para serem apresentados neste estudo. Foi definido como recorte temporal os anos de 2008, 2012, 2016 e 2020, com intuito de apresentar as variações que aconteceram nestes quatro anos supracitados. A justificativa para a escolha dos anos deve-se ao desempenho das exportações entre os anos de 2008 e 2020. Ao longo desse período, o País elevou as suas exportações rapidamente, em virtude da alta dos preços das commodities internacionais, experimentando também períodos de recessão. Alguns fatores, como já mencionados na seção sobre a conjuntura econômica brasileira, tiveram influência sobre as exportações nacionais como: o crescimento da demanda da China e a recuperação da economia dos países da América Latina. Ademais, as exportações de minério de ferro (um dos principais produtos da pauta de exportações do Brasil e de Minas Gerais) também foram responsáveis pelo êxito na receita das exportações brasileiras (REVISTA NEGÓCIOS, 2017).

Vale ressaltar que a mineradora Vale é a maior produtora de minério do mundo e possui uma grande parcela dos embarques da commodity no Brasil. Logo, como Minas Gerais possui a bonança mineral e, o setor extrativo mineral contribui para o desempenho de sua economia regional, o artigo contribui para acompanhar a evolução desse setor e identificar os setores que contribuem para o desenvolvimento econômico do estado.

O objetivo da análise é avaliar o cenário não somente do setor extrativo mineral, mas a contribuição de todos os setores para o desempenho

\footnotetext{
${ }^{3}$ Os dezesseis setores são representados por: 72 Ferro fundido, ferro e aço; 26 Minérios, escórias e cinzas; 09 Café, chá, mate e especiarias; 87 Veículos automóveis, tratores, ciclos e outros veículos terrestres, suas partes e acessórios; 28 Produtos químicos inorgânicos; compostos inorgânicos ou orgânicos de metais preciosos, de elementos radioativos, de metais das terras raras ou de isótopos; 84 Reatores nucleares, caldeiras, máquinas, aparelhos e instrumentos mecânicos, e suas partes; 71 Pérolas naturais ou cultivadas, pedras preciosas ou semipreciosas e semelhantes, metais preciosos, metais folheados ou chapeados de metais preciosos (plaquê), e suas obras; bijuterias; moedas; 47 Pastas de madeira ou de outras matérias fibrosas celulósicas; papel ou cartão para reciclar (desperdícios e aparas); 17 Açúcares e produtos de confeitaria; 73 Obras de ferro fundido, ferro ou aço; 02 Carnes e miudezas, comestíveis; 85 Máquinas, aparelhos e materiais elétricos, e suas partes; aparelhos de gravação ou de reprodução de som, aparelhos de gravação ou de reprodução de imagens e de som em televisão, e suas partes e acessórios; 79 Zinco e suas obras; 12 Sementes e frutos oleaginosos; grãos, sementes e frutos diversos; plantas industriais ou medicinais; palhas e forragens; 81 Outros metais comuns; obras dessas matérias; 68 Obras de pedra, gesso, cimento, amianto, mica ou de matérias semelhantes.
} 
macroeconômico do Estado. Destarte, durante o período sob análise não houve mudanças significativas no volume e na pauta de exportações em Minas Gerais. Desse modo, as análises escalonadas dos quatro períodos permitirão avaliar e comparar a direção, o comportamento, as participações e a competitividade dos setores econômicos nas exportações do estado.

\section{Característica do estudo sobre shift-share}

O desenvolvimento deste estudo fundamenta-se na aplicação do método shift-share. Esta metodologia, também conhecida como método diferencialestrutural, tem por finalidade descrever o crescimento econômico regional em termos de sua estrutura produtiva

Um dos argumentos comuns de crítica à interpretação dos resultados obtidos pela aplicação do método shift-share é que os valores da variação diferencial na exportação regional não são devidos apenas ao dinamismo especial do setor na região $\left(r_{i j}-r_{i t}\right)$, mas também ao grau de especialização da exportação regional nesse setor. Em outras palavras, o efeito competitivo, tal como é usualmente formulado, é influenciado e interligado com o efeito estrutural. Ao propor a criação da exportação homotética e a sua utilização para exprimir o efeito competitivo, ficando este sem a influência do efeito estrutural.

Ademais, o método shift-share analisa as variações a partir dos efeitos estrutural e diferencial. O primeiro é o reflexo na mudança atribuída à configuração produtiva da região (diferença de dinamismo entre a região e a sua referência). Já o segundo, refere-se à mudança que ocorre em consequência do crescimento desigual do setor produtivo em âmbito regional e nacional (vantagens e desvantagens da economia regional).

É oportuno ressaltar que o método shift-share demonstra a variação presente líquida (VPL) sendo o valor total da variável base utilizada em uma determinada região, no qual é elaborada pelos fatores estrutural e diferencial. O VPL pode ser tanto positivo como negativo. Contudo, não existe um equilíbrio entre os fatores, podendo ocorrer de uma região ter grandes vantagens locacionais que sejam suficientes para superar um efeito estrutural negativo, ou possuir vantagens locacionais, que não permitam chegar a uma dinâmica que superem o efeito estrutural negativo. Essas hipóteses também podem ocorrer de maneira contrária, com desvantagem locacional e efeito estrutural positivo, por exemplo. Em suma, 
seria exatamente essa variação que irá determinar se o VPL será positivo ou negativo para a região analisada, o que mostra que o método oferece uma análise desagregada entre setores e regiões.

De acordo com Haddad (1989), deve-se considerar duas limitações do método de shift-share. A primeira delas refere-se quando a análise não considera mudanças na estrutura de exportações das mesorregiões sob o período em análise, em outras palavras, entre 0 ano final e o ano inicial. Assim, o viés na análise dos efeitos ocorre quanto maior for o período e as mudanças significativas não forem consideradas. A segunda limitação baseia-se na dependência dos efeitos diferencial e estrutural nas exportações no ano base. Deste modo, para transpor as duas limitações apontadas quanto ao método shift-share, utilizou-se a proposta de Esteban-Marquillas (1972) no presente trabalho. A proposta de Esteban-Marquillas (1972), formalizadas nas equações 1 a 7, permitem suprimir da posição competitiva a influência estrutural.

Logo, com o método diferencial-estrutural proposto por Esteban-Marquillas (1972) pode-se realizar análises a fim de verificar variações que ocorrem em fatores de crescimento das exportações, emprego, renda, localização, produtividade, entre outros, em uma base regional/setorial. O método permite utilizar vários elementos sem perder o foco da análise estipulada e sem alterar sua metodologia. Porém, esse caso somente é possível quando utilizadas variações econômicas, sem resultar em alterações nelas.

No presente estudo, inicialmente foi calculado shift-share por meio da variação total (VT), taxas regionais de crescimento das exportações por setor e região (rij), Variação Regional (R), Variação líquida total (VT - R), Variação estrutural (E), Variação Diferencial (D) (HADDAD, 1989).

Em que: $R$ = variação regional = acréscimo de exportações que teria ocorrido se a mesorregião crescesse à taxa de crescimento do total do emprego nacional no período; $E$ = variação estrutural = representa a variação no crescimento (positiva ou negativa) que uma região poderia ter como resultado de sua composição industrial, isto é, a participação relativa dos setores dinâmicos ou de crescimento lento; $\mathrm{C}=$ efeito competitivo $=$ efeito diferencial ou competitivo mostra o acréscimo ou decréscimo da exportação na mesorregião, identificando aumento ou queda dessa exportação no nível nacional; $A=$ efeito alocação= indica se a mesorregião é especializada e quais exportações apresentam melhores vantagens competitivas. 
Onde VT= variação total $=$ a diferença entre as exportações do período final e inicial na mesorregião;

$$
\underbrace{\sum_{i} E_{i j}^{1}-\sum_{i} E_{i j}^{0}}_{V T}
$$

rij= a divisão entre as exportações do período final e inicial na mesorregião;

$$
\underbrace{\sum_{i} E_{i j}^{1} / \sum_{i} E_{i j}^{0}}_{r i j}
$$

$\mathrm{R}=$ resultado do somatório do total da taxa regional de crescimento das exportações da mesorregião menos um, resultado multiplicado pelas exportações do período inicial;

$$
\underbrace{\sum_{i} E_{i j}^{0}\left(r_{t t}-1\right)}_{R}
$$

VT - R= diferença entre variação total e variação regional;

$$
\underbrace{\sum_{i} E_{i j}^{1}-\sum_{i} E_{i j}^{0}}_{V T}-\underbrace{\sum_{i} E_{i j}^{0}\left(r_{t t}-1\right)}_{R}
$$

$E=$ corresponde à variação da exportação do setor i da região j que teria ocorrido caso ele crescesse à taxa nacional;

$$
\underbrace{\sum_{i} E_{i j}^{0}\left(r_{i t}-r_{t t}\right)}_{E}
$$

$D=$ corresponde à variação da exportação do setor i da região j que teria ocorrido caso ele crescesse no nível da mesorregião;

$$
\underbrace{\sum_{i} E_{i j}^{0}\left(r_{i t}-r_{t t}\right)}_{D}
$$

Logo após os cálculos, foi verificada a consistência dos dados, para afirmar a validade das operações numéricas. Para encontrar a consistência igual à zero, é necessário que o somatório da variação estrutural com a variação diferencial tem que ser igual à variação líquida total, isto é, Consistência $=(E+D)=V L T$. 
Representando o ano inicial (2008) por 0 e o ano final (2012) por 1, por exemplo, e definindo os componentes do crescimento como: variação regional $(R)$, variação estrutural $(E)$, efeito competitivo $(C)$ e efeito alocação $(A)$, o método pode ser descrito como:

$\sum_{i} E_{i j}^{1}-\sum_{i} E_{i j}^{0}-\sum_{i} E_{i j}^{0}\left(r_{t t}-1\right)=$

VT

$\mathrm{R}$

$$
\begin{aligned}
& \sum_{\mathrm{i}} E_{\mathrm{ij}}^{0}\left(r_{\mathrm{it}}-r_{\mathrm{tt}}\right)+\sum_{0} E_{i j}^{0}\left(r_{i j}-r_{\mathrm{tt}}\right) \\
& \mathrm{E} \quad \mathrm{C} \\
& +\sum_{i}\left[\left(E_{i j}^{1}-E_{i j}^{1}\right)-\left(E_{i j}^{0}-E_{i j}^{0}\right)\right]_{\cdot\left(r_{i j}-r_{\mathrm{it}}\right)}
\end{aligned}
$$

A

A Tabela 1 descreve as possíveis combinações que podem ser obtidas por meio da análise do efeito alocação. Os critérios de análise dos resultados envolvem verificar os setores que apresentaram, nos anos do período considerado (2008 a 2020), Vantagens Comparativas Reveladas (VCRs) elevadas, chamados setores com especialização permanente. Também procurou-se identificar os setores que perderam, ou seja, deixaram de ser especializados, ou ganharam especialização, no decorrer do período e, por último, os setores que apresentaram Vantagens Comparativas Reveladas (VCRs) elevadas, em algum ano do período, chamados de surtos de especialização. Considerar estes níveis de hierarquização tem como único

\begin{tabular}{|c|c|c|c|}
\hline \multirow[b]{2}{*}{ Alternativas } & \multirow{2}{*}{$\begin{array}{l}\text { Efeito } \\
\text { Alocação }\end{array}$} & \multicolumn{2}{|l|}{ Componentes } \\
\hline & & Especialização & $\begin{array}{l}\text { Vantagem } \\
\text { Competitiva }\end{array}$ \\
\hline $\begin{array}{l}\text { Desvantagem competitiva, } \\
\text { especializado }\end{array}$ & Negativo & + & - \\
\hline $\begin{array}{l}\text { Desvantagem competitiva, não } \\
\text { especializado }\end{array}$ & Positivo & - & - \\
\hline
\end{tabular}
propósito auxiliar na constatação do que mudou (e se realmente houve alteração), na inserção externa do Estado de Minas Gerais no período.

Tabela 1 - Classificações das regiões segundo o Efeito Alocação 


\begin{tabular}{|l|l|l|l|}
$\begin{array}{l}\text { Vantagem competitiva, não } \\
\text { especializado }\end{array}$ & Negativo & - & + \\
\hline $\begin{array}{l}\text { Vantagem competitiva, } \\
\text { especializado }\end{array}$ & Positivo & + & + \\
\hline
\end{tabular}

Fonte: Adaptado de HADDAD, 1989.

\section{Resultados}

Com base nos dados da AliceWeb, entre as doze regiões analisadas no estudo $^{4}$, selecionou-se os dezesseis setores que mais exportaram em Minas Gerais, nos anos de 2008, 2012, 2016 e 2020. Todos os setores possuem relevância em todos os anos, com a ressalva de apenas algumas mudanças no ranking na pauta de exportações.

Os primeiros resultados, exibidos nos Quadro 1, 2 e 3, exibem as principais características encontradas no trabalho em relação ao dinamismo dos setores de exportação das mesorregiões mineiras. As células em cinza representam os setores nos quais as mesorregiões apresentaram vantagens comparativas especializadas (VCE). Os setores em azul indicam que há vantagens comparativas não especializadas (VCNE), demonstrando uma predisposição do setor a se tornar dinâmico naquela mesorregião. As células na cor verde referem-se aos setores cujo desempenho é de desvantagem comparativa especializada (DCE), expressando uma predisposição à estagnação das exportações desse setor naquela mesorregião. Por fim, os setores cujas células estão em branco representam uma situação de desvantagem comparativa não especializada (DCNE), em que caracteriza o mais difícil cenário, pois indica estagnação das exportações do setor naquela mesorregião.

Observando-se os resultados do Quadro 1, que representa os períodos 2008 e 2012, nota-se que determinados setores são mais dinâmicos em determinadas mesorregiões em relação a outras. Tal resultado, baseia-se em um setor cujas exportações apresentaram crescimento nessa mesorregião acima da média do Estado (VCE), como por exemplo: os setores de Minérios, escórias e cinzas (26), Ferro fundidos (72), Máquinas, aparelhos e materiais elétricos (85) e Obras de pedra (68), muito presentes na mesorregião Metropolitana de Belo Horizonte (MBH). Pode-

\footnotetext{
${ }^{4}$ As doze regiões mencionadas são: Metropolitana de Belo Horizonte; Sul e Sudoeste de Minas; Vale do Rio Doce; Triângulo Mineiro e Alto Paranaíba; Zona da Mata; Oeste de Minas; Norte de Minas; Noroeste de Minas; Central Mineira; Campo das Vertentes; Vale do Mucuri e Jequitinhonha.
} 
se afirmar que essa mesorregião apresenta vantagem comparativa especializadas e especialização na exportação desses quatro setores, quando comparado com as demais mesorregiões de Minas Gerais.

Quando uma mesorregião apresenta desvantagens comparativas não especializadas na exportação, entende-se que as exportações desse setor na mesorregião cresceram menos que no Estado. Vale lembrar que a sigla VCNE indica dinamismo e a sigla DCE indica estagnação. Assim, verifica-se que a mesorregião $\mathrm{MBH}$, por exemplo, agrega vantagens diversas e esse resultado pode ser corroborado pela importância da mesorregião, que abriga sedes regionais de grandes corporações da mineração mundial e de prestadoras de serviços associadas (NAHAS et al., 2019). Desta forma, o resultado em relação às vantagens observadas converge com o peso da mesorregião sobre as exportações nos setores de mineração.

Quanto às demais mesorregiões, verifica-se que o setor de Veículos automotores (87) é representado grande parte pelas vantagens comparativas não especializadas (VCNE), corroborando a hipótese do dinamismo de nove mesorregiões. É o caso também, por exemplo, do setor exportador de Pastas de madeira ou de outras matérias fibrosas celulósicas (47), que pode ser considerado com o um setor chave para a economia mineira. Seu dinamismo reflete tanto para as variáveis de emprego e exportação, proporcionando também externalidades dinâmicas de especialização e encadeamentos produtivos intraestaduais (NAHAS et al., 2019). 
Quadro 1 - Setores de exportação estagnados e dinâmicos- Minas Gerais- 2008/2012 ${ }^{5}$

\begin{tabular}{|c|c|c|c|c|c|c|c|c|c|c|c|c|}
\hline $\begin{array}{c}\text { Microrregiões / } \\
\text { Setores }\end{array}$ & CV & CM & JQTN & $\mathrm{MBH}$ & NODM & NDM & ODM & SSM & TMAP & VDM & VRD & ZDM \\
\hline 72 & VCNE & DCNE & /CNE & DCNE & VCNE & VCNE & DCE & VCNE & VCE & VCNE & DCE & DCNE \\
\hline 26 & VCNE & DCNE & DCNE & VCE & DCNE & DCNE & DCNE & DCNE & DCNE & DCNE & DCNE & DCNE \\
\hline 9 & DCNE & DCNE & DCE & VCNE & DCNE & DCNE & VCE & DCE & VCNE & DCNE & VCNE & DCE \\
\hline 87 & VCE & VCNE & VCNE & VCNE & DCNE & VCNE & VCNE & VCNE & VCNE & VCNE & VCNE & DCE \\
\hline 28 & VCE & DCE & DCNE & VCNE & DCNE & DCE & DCNE & DCNE & VCNE & DCNE & DCNE & DCE \\
\hline 84 & VCNE & DCNE & DCNE & DCE & DCNE & VCNE & DCNE & VCE & DCNE & DCNE & VCNE & VCNE \\
\hline 71 & VCNE & DCE & VCE & DCE & VCE & DCNE & DCE & DCNE & DCNE & DCE & DCNE & DCNE \\
\hline 47 & VCNE & VCNE & VCNE & VCNE & DCNE & DCNE & DCNE & VCNE & DCNE & DCNE & DCE & VCNE \\
\hline 17 & DCNE & VCE & DCNE & DCNE & VCNE & DCNE & VCNE & DCNE & DCE & VCNE & DCNE & DCNE \\
\hline 73 & VCNE & VCNE & DCNE & VCE & VCNE & DCNE & DCE & VCNE & DCNE & DCNE & DCNE & DCNE \\
\hline 2 & DCE & DCNE & DCNE & DCNE & DCNE & DCE & DCNE & VCNE & VCE & DCE & DCNE & DCNE \\
\hline 85 & VCNE & DCNE & DCNE & VCE & DCNE & DCNE & DCNE & DCE & DCNE & DCNE & VCNE & DCNE \\
\hline 79 & DCNE & VCE & DCNE & VCNE & DCNE & DCNE & DCNE & VCNE & DCNE & DCNE & DCNE & DCE \\
\hline 12 & DCNE & DCNE & DCNE & DCNE & VCE & VCNE & VCNE & DCE & DCE & DCNE & DCNE & DCNE \\
\hline 81 & DCE & DCNE & DCNE & VCNE & DCNE & DCE & DCNE & DCNE & VCE & DCNE & DCNE & DCNE \\
\hline 68 & VCNE & DCE & VCE & VCE & VCNE & VCNE & DCNE & DCE & VCNE & VCNE & DCNE & DCE \\
\hline
\end{tabular}

Fonte: Elaboração própria com base na pesquisa realizada.

Quanto aos resultados no Quadro 2, observa-se que a maioria das mesorregiões são caracterizadas pelas Vantagens Comparativas Não Especializadas (VCNE), indicando que entre os anos 2012 e 2016 houve um ambiente de dinamismo econômico nessas regiões, como por exemplo nas mesorregiões: Central Mineira, Jequitinhonha e Vale do Mucuri. Os setores que mais contribuíram para esse desempenho foram: Pastas de madeira ou de outras matérias fibrosas celulósicas (47) e Outros metais comuns; obras dessas matérias (81). Por outro lado, as mesorregiões que tiveram uma atuação fraca foram configuradas pelas desvantagens comparativas não especializadas (DCNE) e representaram uma inércia das atividades, como as mesorregiões: Sul e Sudoeste de Minas (SSM), Metropolitana de Belo Horizonte (MBH) e Oeste de Minas (ODM).

Vale ressaltar que as regiões supracitadas obtiveram esses resultados especialmente para os setores: Ferro fundido, ferro e aço (72) e Minérios, escórias e cinzas (26). Ademais, o desempenho negativo nessa pauta de exportação pode ter sido reflexo do rompimento da barragem de ocorrido em 2015, na cidade de Mariana (também conhecido como a tragédia em Mariana). As atividades ligadas à mineração possuem somente no estado de Minas Gerais 315 barragens e, as mesorregiões caracterizadas por DCNE obtiveram impacto negativos na participação

\footnotetext{
5Legenda: CV- Campos das Vertentes, CM- Central Mineira, JQTN- Jequitinhonha, MBHMetropolitana de Belo Horizonte, NODM- Noroeste de Minas, NDM- Norte de Minas, ODM- Oeste de Minas, SSM- Sul e Sudoeste de Minas, TMAP- Triângulo Mineiro e Alto Paranaíba, VDM- Vale do Mucuri, VRD- Vale do Rio Doce e ZDM- Zona da Mata.
} 
do setor extrativista mineral em seu produto interno bruto (PIB) (CASTRO e ALMEIDA, 2019). A cidade de Mariana, mais especificamente no distrito de Bento Rodrigues onde ocorreu o acidente, mais os distritos, os municípios e os estados vizinhos sentiram os efeitos ambientais negativos, as alterações em seus patrimônios históricos e culturais, além da perda de dezenove vidas (VEJA, 2015).

Quadro 2 - Setores de exportação estagnados e dinâmicos- Minas Gerais- 2012/2016

\begin{tabular}{|c|c|c|c|c|c|c|c|c|c|c|c|c|}
\hline $\begin{array}{c}\begin{array}{c}\text { Microrregiões / } \\
\text { Setores }\end{array} \\
\end{array}$ & CV & CM & JQTN & MBH & NODM & NDM & ODM & SSM & TMAP & VDM & VRD & ZDM \\
\hline 72 & DCE & VCNE & VCNE & DCNE & VCNE & DCE & VCE & DCNE & VCE & VCNE & VCE & $\begin{array}{l}\text { VNE } \\
\text {. }\end{array}$ \\
\hline 26 & VCNE & VCNE & VCNE & VCE & VCNE & DCNE & DCNE & DCNE & VCNE & VCNE & VCNE & VCNE \\
\hline 9 & VCNE & VCNE & DCE & DCNE & DCNE & VCNE & DCE & DCE & VCNE & VCNE & DCNE & VCE \\
\hline 87 & DCE & VCNE & VCNE & VCE & VCNE & DCE & DCNE & DCNE & DCNE & VCNE & DCNE & VCNE \\
\hline 28 & DCE & VCNE & VCNE & VCNE & VCNE & DCE & DCNE & VCNE & DCE & VCNE & VCNE & VCE \\
\hline 84 & VCNE & VCNE & VCNE & DCE & VCNE & VCNE & DCNE & VCE & VCNE & VCNE & DCNE & DCNE \\
\hline 71 & DCNE & VCNE & VCE & DCNE & VCE & VCNE & VCE & DCNE & VCNE & DCE & VCNE & VCNE \\
\hline 47 & VCNE & VCNE & VCNE & DCNE & VCNE & VCNE & VCNE & DCNE & VCNE & VCNE & VCE & VCNE \\
\hline 17 & VCNE & DCE & VCNE & DCNE & VCE & VCNE & DCE & DCNE & VCE & DCE & VCNE & VCNE \\
\hline 73 & DCNE & DCNE & VCNE & VCE & DCNE & VCNE & DCE & DCNE & DCNE & VCNE & DCNE & DCNE \\
\hline 2 & VCE & VCNE & VCNE & VCNE & VCNE & VCNE & VCNE & VCNE & DCE & VCE & VCNE & VCE \\
\hline 85 & DCNE & VCNE & VCNE & DCE & VCNE & DCNE & VCNE & VCE & DCNE & VCNE & DCNE & DCNE \\
\hline 79 & DCNE & VCE & DCNE & VCNE & DCNE & DCNE & DCNE & DCNE & DCNE & DCNE & DCNE & DCE \\
\hline 12 & DCNE & DCNE & DCNE & DCNE & DCE & DCE & DCE & VCNE & VCE & DCNE & VCNE & DCNE \\
\hline 81 & DCNE & VCNE & VCNE & VCNE & VCNE & VCE & VCNE & VCNE & VCE & VCNE & VCNE & VCNE \\
\hline 68 & VCE & DCE & VCE & VCE & VCNE & DCE & DCNE & DCE & VCNE & VCNE & VCNE & DCE \\
\hline
\end{tabular}

Fonte: Elaboração própria com base na pesquisa realizada.

Em relação ao Quadro 3, referente aos anos 2016 e 2020, observa-se que as mesorregiões que se destacaram pelas VCNEs foram: Central Mineira, Oeste de Minas e Zona da Mata. Quanto as DCEs, as mesorregiões da Zona da Mata, Metropolita de Belo Horizonte e Campo das Vertentes tiveram um desempenho de destaque em relação às outras regiões. De acordo com as VCEs, as mesorregiões Metropolitana de Belo Horizonte, Norte de Minas e Triângulo Mineiro e Alto Paranaíba. Por fim, as mesorregiões Jequitinhonha, Vale do Mucuri e Norte de Minas obtiveram um fraco desempenho das exportações no cômputo das DCNEs. Os setores que proporcionaram esse efeito nas três mesorregiões foram: Ferro fundido, ferro e aço (72), Açúcares e produtos de confeitaria (17) e Obras de ferro fundido, ferro ou aço (73). Observou-se também que as mesorregiões como a Zona da Mata e a Metropolitana de Belo Horizonte apresentaram duas características em comum, tanto em relação às suas Vantagens Comparativas Não Especializadas e às Vantagens Comparativas Especializadas, confirmando a relação de que as cidades tanto podem ser especializadas e diversificadas ao mesmo tempo (MONTENEGRO, GONÇALVES e ALMEIDA, 2011).

Da mesma forma que no período anterior (2012-2016) ocorreu a tragédia em Mariana, nos anos entre 2016 e 2020, o estado de Minas Gerais sentiu os efeitos de 
outro rompimento de barragem ocorrido no município de Brumadinho, no ano de 2019. Como ressaltado por Nahas (2010) e Nahas et al., (2019) e confirmado por (Coelho, 2018), a mesorregião que pertence a Mariana e Brumadinho, Metropolitana de Belo Horizonte, é altamente dependente do setor extrativo mineral. Com o rompimento das barragens, os efeitos da minério-dependência sobre outras atividades econômicas foram negativos nos municípios atingidos e nas localidades vizinhas, em que as economias locais dependiam eram diretamente ligadas às mineradoras e/ou à cadeia produtiva do setor de mineração (setores de bens e serviços) (COELHO, 2018).

Além disso, no ano de 2020, conforme descrito anteriormente, a recessão provocada pelos efeitos da pandemia do COVID-19, reforçaram a diminuição da intensidade da pauta de exportações nacionais (FUNCEX, 2020). Em Minas Gerais, o minério de ferro e o café foram os dois produtos mais exportados pelo Estado, sendo a China a maior demandante de minério. Contudo, houve queda de $2,6 \%$ das exportações totais, em relação ano de 2019 (DIÁRIO DO COMÉRCIO, 2020); RIBEIRO et al., (2020).

Quadro 3 - Setores de exportação estagnados e dinâmicos- Minas Gerais- 2016/2020

\begin{tabular}{|c|c|c|c|c|c|c|c|c|c|c|c|c|}
\hline $\begin{array}{c}\text { Microrregiões / } \\
\text { Setores }\end{array}$ & CV & $\mathrm{CM}$ & JQTN & $\mathrm{MBH}$ & NDM & NDM & ODM & SSM & TMAP & VDM & VRD & ZDM \\
\hline 72 & VCE & VCNE & DCNE & DCNE & DCNE & VCNE & VCE & VCNE & VCE & DCNE & DCE & DCNE \\
\hline 26 & DCNE & VCNE & VCNE & VCE & DCNE & VCNE & DCNE & DCNE & VCNE & VCNE & DCNE & VCNE \\
\hline 9 & VCNE & DCNE & DCE & DCNE & VCNE & VCNE & VCNE & VCE & DCNE & DCNE & VCNE & DCE \\
\hline 87 & VCE & VCNE & VCNE & DCE & VCNE & VCNE & VCNE & VCNE & VCNE & VCNE & VCNE & DCE \\
\hline 28 & DCE & VCNE & VCNE & VCNE & VCNE & VCE & VCNE & DCE & DCNE & VCNE & VCNE & DCE \\
\hline 84 & DCNE & VCNE & DCNE & VCE & DCNE & DCNE & VCNE & DCE & DCNE & DCNE & DCNE & VCNE \\
\hline 71 & VCNE & DCNE & DCE & DCNE & VCE & VCE & DCE & VCNE & DCNE & DCE & DCNE & VCNE \\
\hline 47 & VCNE & VCNE & VCNE & VCNE & VCNE & VCNE & VCNE & VCNE & VCNE & VCNE & DCE & VCNE \\
\hline 17 & DCNE & VCNE & DCNE & VCNE & DCE & DCNE & VCNE & DCNE & DCE & DCNE & DCNE & VCNE \\
\hline 73 & DCNE & DCNE & DCNE & DCE & DCNE & DCNE & DCE & VCNE & VCNE & DCNE & VCNE & DCNE \\
\hline 2 & DCE & DCNE & DCNE & VCNE & DCNE & DCE & VCNE & DCNE & VCE & DCE & VCNE & VCNE \\
\hline 85 & VCNE & VCNE & VCNE & DCE & VCNE & VCNE & VCE & VCE & VCNE & VCNE & VCNE & VCNE \\
\hline 79 & DCNE & VCE & DCNE & DCNE & DCNE & DCNE & DCNE & DCNE & DCNE & DCNE & DCNE & DCE \\
\hline 12 & VCNE & VCNE & DCNE & VCNE & VCE & VCE & VCNE & DCNE & DCE & DCNE & DCNE & VCNE \\
\hline 81 & DCNE & DCNE & VCNE & VCNE & VCNE & DCE & VCNE & VCNE & VCE & VCNE & VCNE & VCNE \\
\hline 68 & DCE & VCE & DCE & VCE & VCNE & DCNE & DCNE & DCNE & DCNE & VCNE & VCNE & DCNE \\
\hline
\end{tabular}

Fonte: Elaboração própria com base na pesquisa realizada.

Como forma de diagnosticar o dinamismo ou a estagnação sob a ótica das mesorregiões mineiras, os Gráficos 1, 2 e 3 apresentam a quantidade de setores dinâmicos. Observa-se que grande parte das mesorregiões no Gráfico 1 se concentra no cômputo representado pelas desvantagens comparativas não especializadas (DCNE). Tal resultado reflete a concentração restrita do setor metalúrgico, em relação aos demais setores exportadores e a limitada diversificação produtiva no Estado, que pode ser justificado pela atratividade do setor Extrativo 
Mineral. Ademais, no período entre os anos 2008 e 2012, o País intensificou o processo de reprimarização da pauta exportadora brasileira (MEYER e PAULA, 2009).

O Gráfico 2, por outro lado, representou no período 2012-2016 um maior peso nas mesorregiões sob a ótica classificação das vantagens comparativas não especializadas (VCNE). Como uma das mesorregiões mais dinâmicas, a mesorregião Metropolitana de Belo Horizonte $(\mathrm{RMBH})$ representou no período cerca de $40 \%$ das exportações da economia mineira. A presença da RMBH no quadrilátero ferrífero garantiu uma participação importante da indústria extrativista mineral no PIB metropolitano.

No tocante, a região do Triângulo Mineiro/Alto Paranaíba teve seu crescimento econômico vinculado ao Estado de São Paulo e à agroindústria moderna, no período entre 2012 e 2016 (Gráfico 2). Vale ressaltar o desempenho quanto ao seu crescimento econômico regional, sob dois aspectos. O primeiro está relacionado ao Triângulo, que ainda possui seu desenvolvimento ligado ao Estado de São Paulo por intermédio da expansão da fronteira agrícola e desconcentração do parque industrial paulista. Na região destaca-se a produção de soja, milho, cana de açúcar, arroz e grande variedade de frutas - o solo e o clima favorecem a cultura com práticas modernas.

Além disso, há um significativo rebanho bovino e criação de aves, bem como uma importante indústria de fertilizantes. O segundo aspecto refere-se ao Alto Paranaíba, cujo crescimento está relacionado à modernização da agricultura e à industrialização, descartando-se também a produção de fertilizantes e o setor agroindustrial. A localização estratégica entre os importantes estados brasileiros, a mão de obra qualificada, as condições perfeitas para o agronegócio e a excelente infraestrutura são os principais diferenciais da região. O Triângulo Mineiro, possui nas indústrias de extrativismo mineral, mecânica e material elétrico e de comunicação a sua maior riqueza. Nos resultados apresentados pelo Shift-Share, observou-se que grande parte da mesorregião possui vantagem competitiva, no entanto, não especializada (ALVES e BARBOSA, 2017).

Em relação à mesorregião Sul e o Sudoeste de Minas Gerais, observou-se que o café da região é a base da sua economia. Considerado a segunda região em importância econômica no Estado, a cafeicultura constituiu-se como base de crescimento da região durante muitos anos (VALE, CALDERARO e FAGUNDES, 
2014). Quanto a mesorregião do Vale do Rio Doce, ela se apresentou entre os períodos analisados com características distintas, isto é, uma parte industrializada e com elevado nível de desenvolvimento, e a outra estagnada. Entre os setores que mais se destacaram pelo dinamismo foram: Minérios, escórias e cinzas (26); Produtos químicos inorgânicos; compostos inorgânicos ou orgânicos de metais preciosos, de elementos radioativos, de metais das terras raras ou de isótopos (28); Pérolas naturais ou cultivadas, pedras preciosas ou semipreciosas e semelhantes, metais preciosos, metais folheados ou chapeados de metais preciosos (plaquê), e suas obras; bijuterias; moedas (71).

Nos três períodos analisados, observou-se que a mesorregião Noroeste de Minas, possui a predominância de setores dinâmicos relacionados à agropecuária, como por exemplo: Café, chá, mate e especiarias (09) e Sementes e frutos oleaginosos (12). Para o desenvolvimento recente da região, houve também a implantação de indústrias de grande porte nos ramos de extração mineral e siderurgia. A região transformou-se com a pecuária extensiva, cedendo lugar à produção de grãos em escala comercial (arroz, feijão, milho e soja). Associado a isto, vem ocorrendo a implantação de indústrias que beneficiam os grãos produzidos na região. É importante ressaltar que a região é responsável por 1,2\% dos empregos formais e de $2,5 \%$ das exportações totais do Estado (ASSOCIAÇÃO MINEIRA DE MUNICÍPIOS, 2014).

Por sua vez, na Zona da Mata, a pauta de exportações é bem diversificada com os setores mais dinâmicos concentrando-se em: café, produtos alimentares, siderurgia e automóveis. A região é caracterizada por $9,5 \%$ dos empregos formais e de $3,2 \%$ das exportações totais do Estado, contudo, vem reduzindo sua participação total (ASSOCIAÇÃO MINEIRA DE MUNICÍPIOS, 2014).

A mesorregião do Campo das Vertentes possui uma peculiaridade quanto ao reconhecimento de Indicação Geográfica tendo o café como produto (AGROLINK, 2020). A região é conhecida pelo clima ameno e características próprias e culturais ligadas à produção do café. Além do produto, verificou-se que os setores exportadores mais dinâmicos no período em estudo: Obras de ferro fundido, ferro ou aço (73) e Pastas de madeira ou de outras matérias fibrosas celulósicas; papel ou cartão para reciclar (desperdícios e aparas) (47), também impulsionaram a economia local. 
Sobre as mesorregiões do Jequitinhonha e do Vale do Mucuri, ambas são próximas e apresentam atividades econômicas de destaque como: agricultura, pecuária, mineração, pedras ornamentais, pedras preciosas, ferro-liga, metalurgia, reflorestamento, têxteis, frutas e minerais não metálicos. Apesar da baixa participação das exportações no Estado ao longo dos anos, as regiões foram responsáveis por exibir setores exportadores dinâmicos como: Veículos automóveis, tratores, ciclos e outros veículos terrestres, suas partes e acessórios (87); Produtos químicos inorgânicos; compostos inorgânicos ou orgânicos de metais preciosos, de elementos radioativos, de metais das terras raras ou de isótopos (28); Reatores nucleares, caldeiras, máquinas, aparelhos e instrumentos mecânicos, e suas partes (84).

Por fim, em Minas Gerais há diferenças regionais de especialização e diversificação na sua pauta de exportações com uma ampla rede de serviços e produtos relacionados principalmente à mineração. De acordo com o desempenho observado para as mesorregiões mineiras, propõe-se ampliar a capacidade da dinâmica local, isto é, concentrar esforços aos setores que são dinâmicos e, amplificar a capacidade de diversificação produtiva de regiões específicas como as mesorregiões de Jequitinhonha, Noroeste de Minas, Norte de Minas, Sul e Sudoeste de Minas e Vale do Mucuri. No caso específico de Minas Gerais, a localização das principais mesorregiões, como é o caso da $\mathrm{RMBH}$, influenciam a dinâmica produtiva das mesorregiões vizinhas, principalmente pelo seu caráter forte das exportações de minério.

Gráfico 1 - Diagnóstico de dinamismo ou estagnação sob a ótica das mesorregiões (20082012)

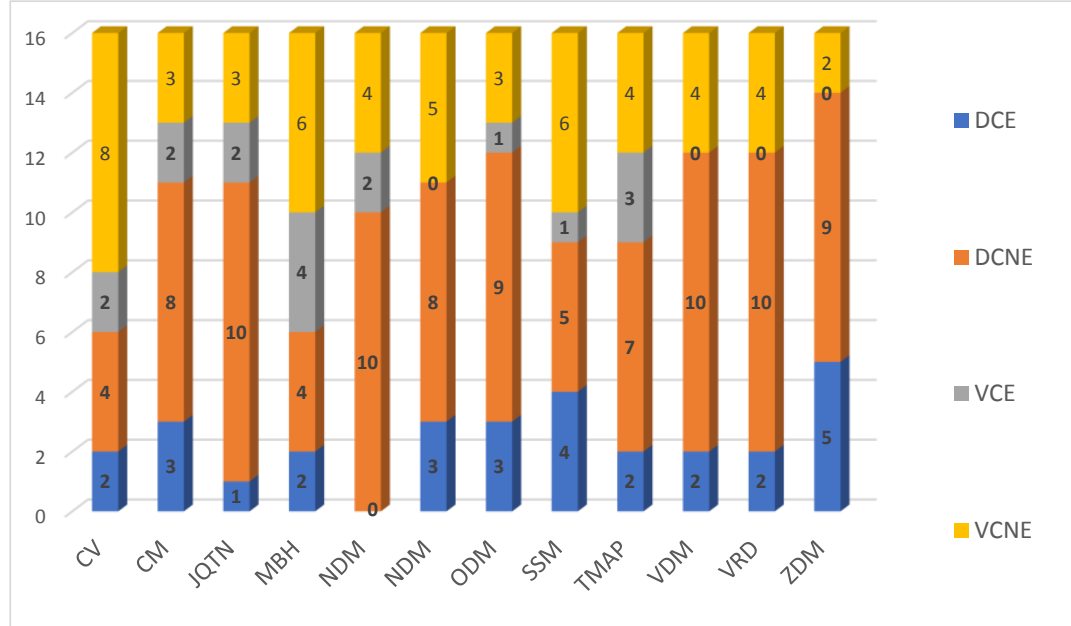

Fonte: Elaboração própria com base na pesquisa realizada. 
Gráfico 2- Diagnóstico de dinamismo ou estagnação sob a ótica das mesorregiões (2012 2016)

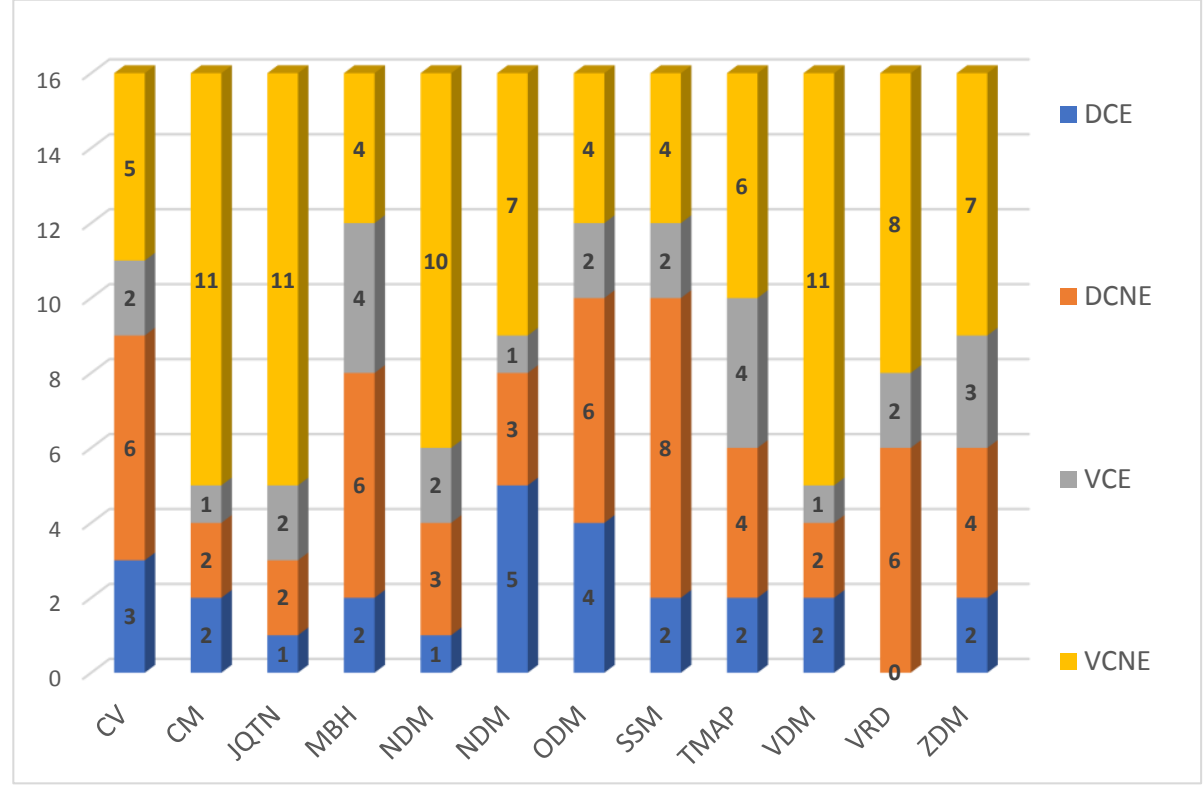

Fonte: Elaboração própria com base na pesquisa realizada.

Gráfico 3 - Diagnóstico de dinamismo ou estagnação sob a ótica das mesorregiões (20162020)

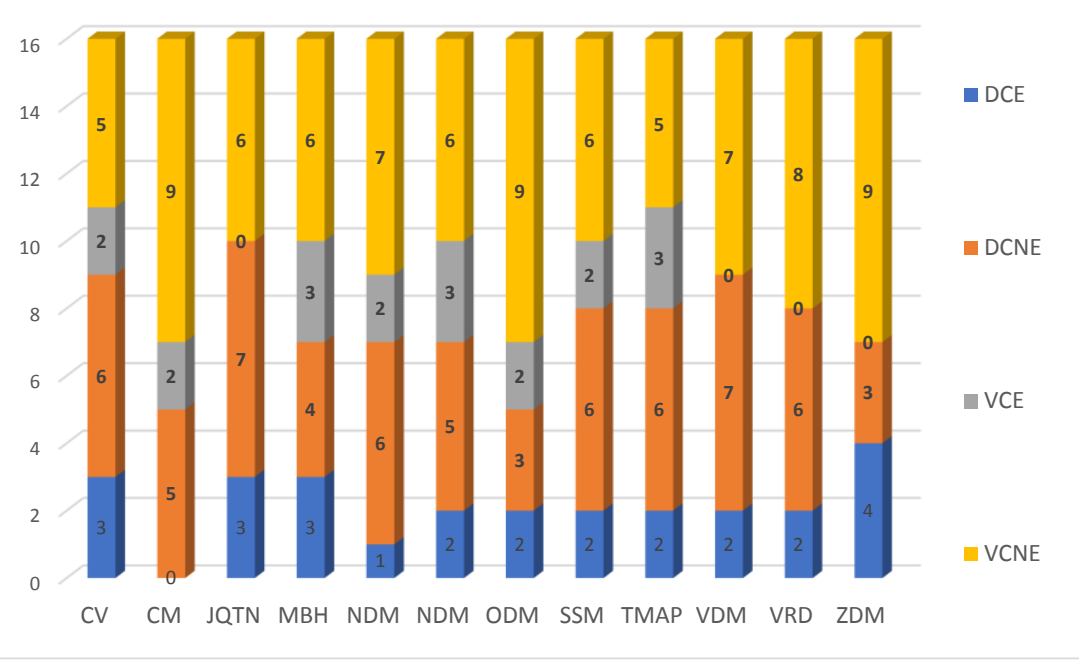

Fonte: Elaboração própria com base na pesquisa realizada.

De modo geral, observa-se que os Gráficos 4, 5 e 6, refletem uma predominância de setores dinâmicos ao longo dos anos, com exceção do primeiro período analisado (2008 e 2012). Os efeitos desse período para a economia brasileira conforme apontado por Salvato, Sant'anna e Da Silva (2008), além do processo de reprimarização da pauta exportadora brasileira, identificado por Meyer e Paula (2009), auxiliam a diagnosticar o comportamento de estagnação 
representados por alguns setores como: Ferro fundido, ferro e aço (72), Máquinas, aparelhos e materiais elétricos, e suas partes (85), Zinco e suas obras (79). Apesar da perda da participação desses setores, Minas Gerais reequilibrou a balança comercial com as exportações de itens como: Veículos automóveis, tratores, ciclos e outros veículos terrestres, suas partes e acessórios (87), Pastas de madeira ou de outras matérias fibrosas celulósicas; papel ou cartão para reciclar (desperdícios e aparas) (47) e Obras de pedra, gesso, cimento, amianto, mica ou de matérias semelhantes (68), porém, manteve-se seu perfil exportador de commodities.

No tocante ao período entre os anos 2012 e 2016 e 2016 e 2020, os efeitos econômicos sobre as exportações das mesorregiões tiveram o reflexo dos desastres ambientais ocorridos nos anos de 2015 e 2019, decorrentes dos rompimentos das barragens nos municípios de Mariana e Brumadinho, respectivamente. Em virtude da mesorregião $(\mathrm{MBH})$ envolver os municípios atingidos pelo acidente, a pauta exportadora principal da referida mesorregião, o setor de mineração, experimentou os impactos negativos da redução das atividades. Os setores atrelados a pauta e que representaram o cômputo das desvantagens comparativas não especializadas (DCNE) foram: Obras de ferro fundido, ferro ou aço (73) e Zinco e suas obras (79). Os resultados supracitados contribuíram também para que outras regiões menos dinâmicas como as mesorregiões de Jequitinhonha e Norte de Minas experimentassem os efeitos negativos em virtude das implicações socioambientais e impactos que transcendem as fronteiras espaço-temporal e territorial (FREITAS et al., 2019).

Além disso, o último período analisado referente aos anos de 2016 e 2020, foi representado por um cenário difícil para a economia de Minas Gerais. Em virtude, dos efeitos do rompimento da barragem em Brumadinho (2019), as consequências econômicas da pandemia do Covid-19 afetaram todas as atividades econômicas mineiras. De modo geral, além dos setores que foram afetados pela queda na produção: Reatores nucleares, caldeiras, máquinas, aparelhos e instrumentos mecânicos, e suas partes (84), Obras de ferro fundido, ferro ou aço, (73) Zinco e suas obras (79), os efeitos sobre o comércio exterior foram observados no aumento do frete, nas operações suspensas e nos containers abandonados (FIEMG, 2020). 
Gráfico 4 - Diagnóstico de dinamismo ou estagnação sob a ótica dos setores (2008-2012)

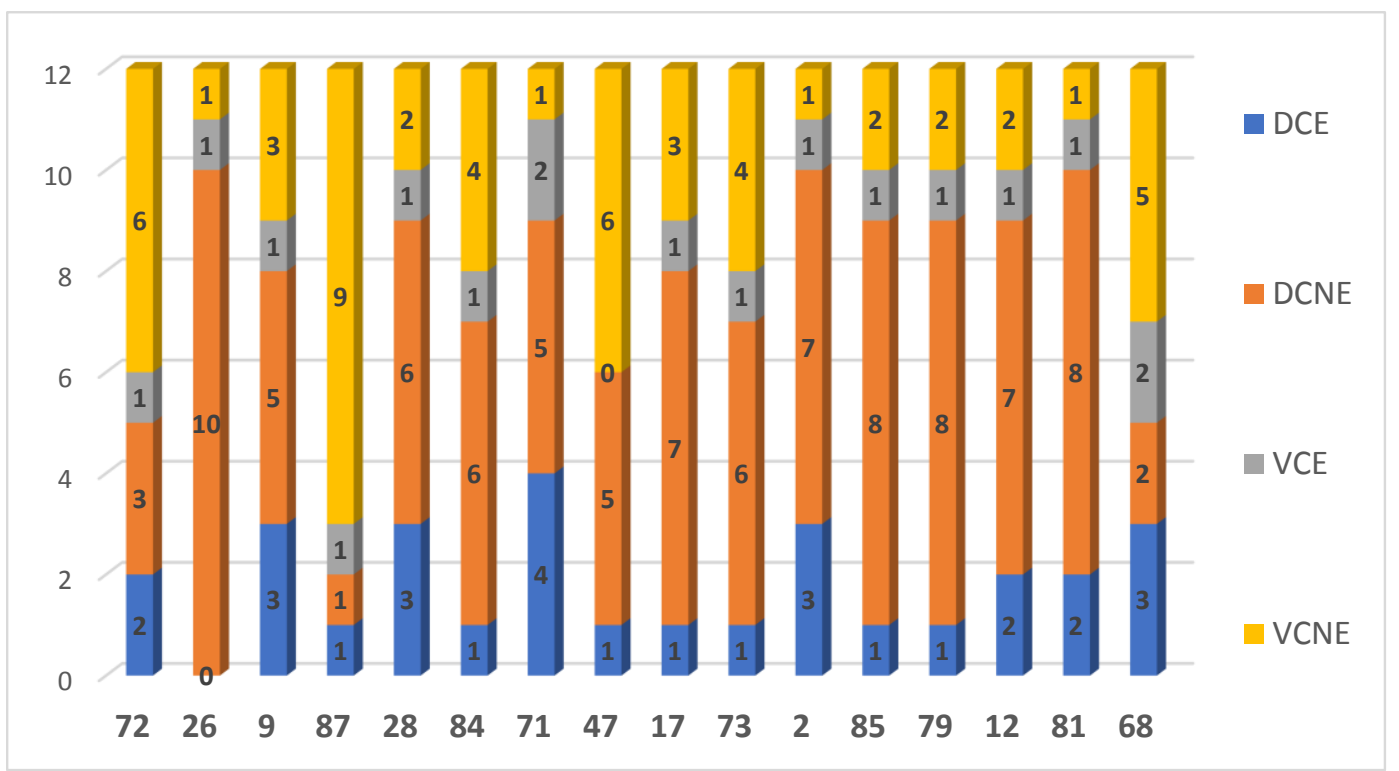

Fonte: Elaboração própria com base na pesquisa realizada.

Gráfico 5 - Diagnóstico de dinamismo ou estagnação sob a ótica dos setores (2012 - 2016)

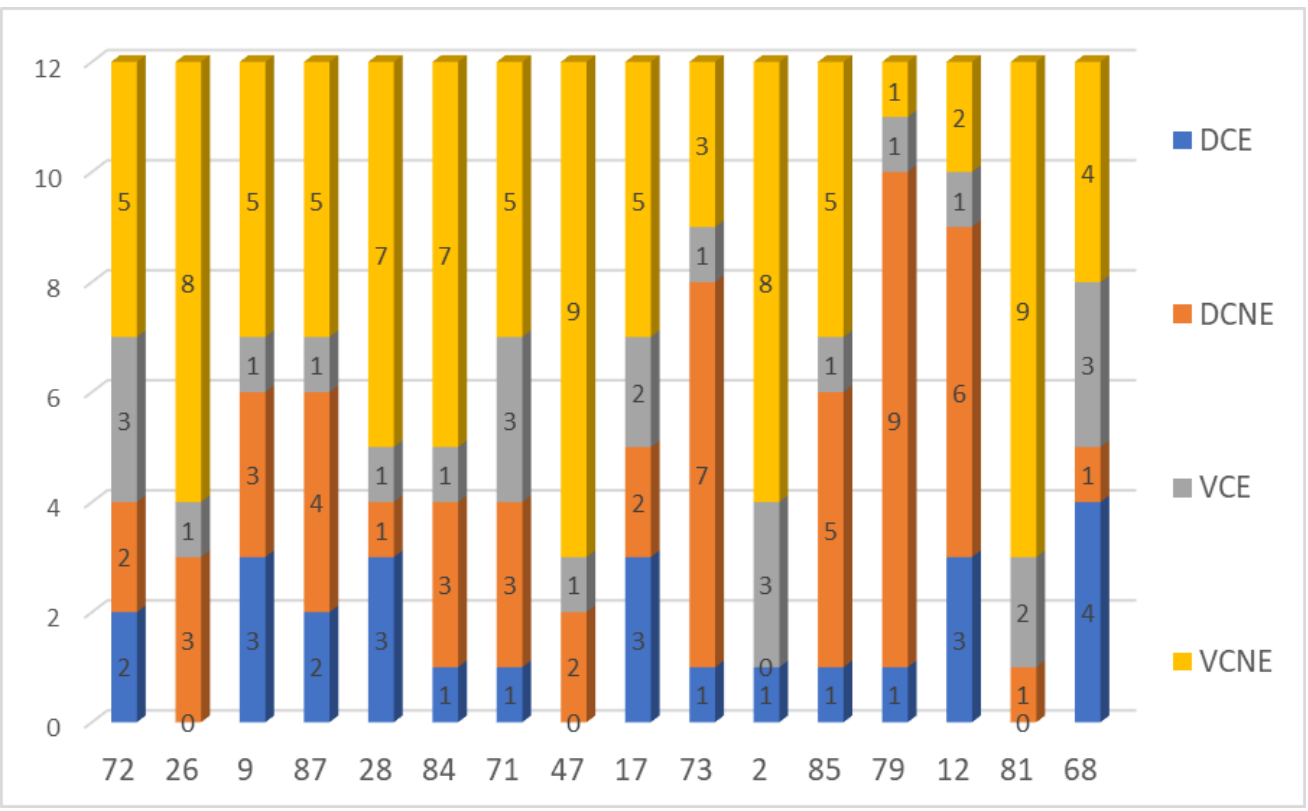

Fonte: Elaboração própria com base na pesquisa realizada. 
Gráfico 6 - Diagnóstico de dinamismo ou estagnação sob a ótica dos setores (2016-2020)

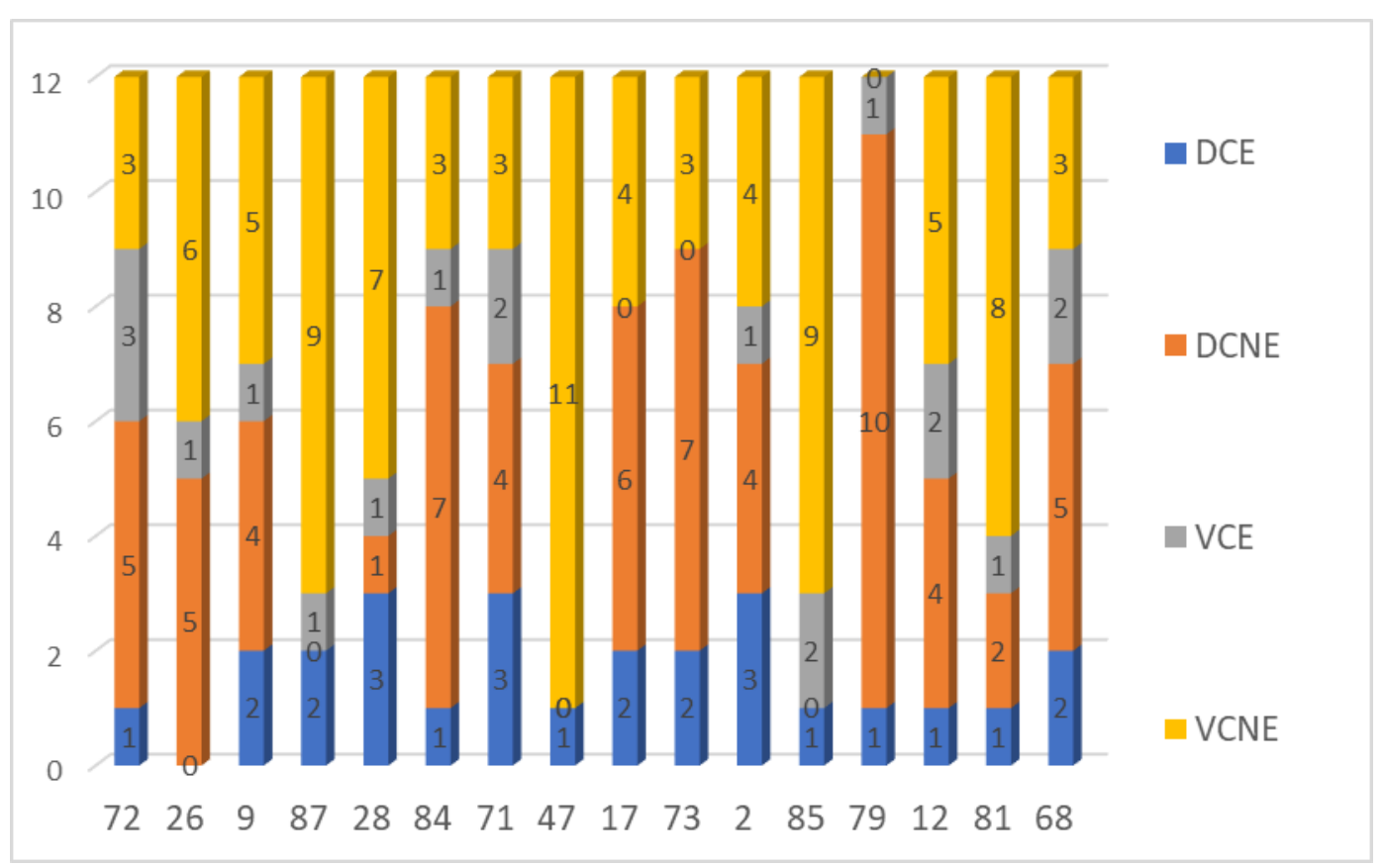

Fonte: Elaboração própria com base na pesquisa realizada.

\section{Considerações finais}

O trabalho teve como objetivo analisar o desempenho de dezesseis setores econômicos das exportações das mesorregiões de Minas Gerais, entre os anos 2008 a 2020 de forma escalonada, por intermédio da análise de shift-share. Observou-se que a reprimarização da pauta das exportações brasileiras foi seguida pelo estado mineiro. Um dos setores de destaque é o mínero-metalúrgico que apresenta grande importância no cenário nacional, em função de sua elevada participação no PIB e nas exportações.

Para Minas Gerais, ao longo dos anos identificou-se que o setor mínerometalúrgico é bastante inclinado ao mercado externo. Atualmente o setor passa por um período de recuperação da crise, principalmente em decorrência dos rompimentos das barragens de Mariana e Brumadinho, cuja velocidade dependerá principalmente da capacidade de reação das economias emergentes. Inicialmente, o bom desempenho da economia chinesa foi determinante para a sustentação dos níveis de produção no setor, de forma que a participação deste país nas exportações atingiu níveis recordes em 2009, por exemplo. As projeções para o crescimento chinês têm sido otimistas, de maneira que a demanda desse país deverá se recuperar em um horizonte de tempo relativamente curto, após a recuperação econômica global devido aos impactos econômicos referentes à pandemia do COVID-19. 
Dessa forma, as perspectivas de crescimento do setor podem ser consideradas otimistas, desde que a economia mundial mostre sinais de recuperação. Por outro lado, deve-se ressaltar que a participação desproporcional da China na importação de produtos menos elaborados sinaliza que essa economia apresenta maior competitividade em relação aos setores da metalurgia comparativamente à economia brasileira.

Quanto aos aspectos regionais, é oportuno ressaltar a influência da Região Metropolitana de Belo Horizonte para as mesorregiões mais próximas e mais economicamente frágeis, como é o caso de Jequitinhonha, Vale do Mucuri e Norte de Minas. Além dos reflexos negativos referentes à contaminação do meio ambiente, as mesorregiões foram comprometidas economicamente, pela diminuição da capacidade de atração de empregos, geração de renda e todo o suporte das economias locais atreladas a exploração mineral. Ademais, a permanência dos danos sofridos nas regiões afeta não somente o ecossistema, mas o intensifica o fluxo migratório para outras regiões, aumenta os empregos informais e contribui para a ocupação desordenada nos centros urbanos.

Logo, para os planejadores de políticas públicas, de acordo com os resultados, compete à política regional selecionar os setores ou indústrias privilegiadas pela política industrial, de acordo com o grau de especialização encontrado. Para o desenvolvimento dessas regiões especializadas, as políticas de desenvolvimento regional deveriam criar condições locais de produção que estivessem de acordo com a política industrial e de exportação da localidade. Isto quer dizer que, a política industrial deva privilegiar a maior eficiência produtiva e competitividade das empresas das mesorregiões (VCNE e VCE).

Para futuras contribuições à literatura empírica da área, pretende-se investigar os efeitos econômicos da pauta das exportações municipais com ferramentas econométricas espaciais. A análise pretendida poderá ajudar a observar o comportamento da região para o período sob estudo. Além disso, possibilitará ampliar a análise e a discussão dos planejadores públicos quanto a geração de novas oportunidades de empregos e negócios para a economia mineira.

\section{REFERÊNCIAS}

AGROLINK. Campo das Vertentes recebe Indicação de Procedência. Região passa a ser mais valorizada por suas características únicas. [s.l: s.n.]. Disponível em: $<$ https://www.agrolink.com.br/noticias/campo-das-vertentes-recebe-indicacao-deprocedencia_442966.html>.

ALVES, F. O.; BARBOSA, D. D. G. A FORÇA DO TRIÂNGULO MINEIRO. [s.I: s.n.].

Disponível em: <https://www.indi.mg.gov.br/a-forca-do-triangulo-mineiro/>. 
ARAÚJO, A. C. M. S.; SARTORI, A. DRAWBACK E O COMÉRCIO EXTERIOR - VISÃO JURÍDICA E OPERACIONAL. São Paulo: [s.n.].

ASSOCIAÇÃO MINEIRA DE MUNICÍPIOS. Caracterização econômica das regiões de planejamento. [s.l: s.n.]. Disponível em: <https://portalamm.org.br/caracterizacaoeconomica-das-regioes-de-planejamento/>.

BRESSER-PEREIRA, L. C. Em busca do desenvolvimento perdido: um projeto novodesenvolvimentista para o Brasil. 1a. ed. [s.l: s.n.].

CASTRO, L. S. DE; ALMEIDA, E. S. DE. Desastres e desempenho econômico: avaliação do impacto do rompimento da barragem de Mariana. Geosul, 2019.

COELHO, T. P. C. Minério-dependência em Brumadinho e Mariana. Lutas Sociais, v. 22, n. 41, p. 252-267, 2018.

DIÁRIO DO COMÉRCIO. Exportações mineiras recuam, mas saldo da balança é positivo. [s.l: s.n.]. Disponível em: <https://diariodocomercio.com.br/economia/exportacoesmineiras-recuam-mas-saldo-da-balanca-e-positivo/>.

DINIZ, C. C. Estado e capital estrangeiro na industrialização mineira. [s.I.] Universidade Estadual de Campinas (UNICAMP), 1981.

DNPM. Sumário Mineral 2016. [s.I: s.n.]. Disponível em:

<file://C:/Users/rosal/AppData/Local/Temp/sumario-mineral-2016.pdf>.

DÓREA, R. J. DOS S. et al. UMA ANÁLISE DAS EXPORTAÇÕES DE MINÉRIO DE FERRO DO ESTADODE MINAS GERAIS SOB A PERSPECTIVA DA VANTAGEMCOMPARATIVA REVELADA E DA TAXA DE COBERTURA, ENTRE OSANOS DE 1997 A 2014XIV Semana de Economia da UESB. Anais...llhéus:

2015Disponível em:

<http://www2.uesb.br/eventos/semana_economia/2015/arquivos/16.pdf>

ENERGIA, M. DE M. E. Sumário Mineral 2014. Brasília: [s.n.]. Disponível em: <http://www.dnpm.gov.br/dnpm/sumarios/sumario-mineral-2014>.

ESTEBAN-MARQUILLAS, J. M. Shift-share analysis revisited. Regional anda Urban Economics, v. 2, n. 3, p. 249-261, 1972.

FIEMG. Crise da Covid-19 e os impactos nas exportações. [s.l: s.n.]. Disponível em: <https://www7.fiemg.com.br/Noticias/Detalhe/crise-da-covid-19-e-os-impactos-nasexportacoes>.

FREITAS, C. M. DE et al. Da Samarco em Mariana Ã Vale em Brumadinho: desastres em barragens de minera $\tilde{A} \S \tilde{A} l$ poundso e SaÃltextordmasculinede Coletiva. Cadernos de SaÃltextordmasculinede PÃltextordmasculineblica, v. 35, 2019.

FUNCEX. BASE DE DADOS FUNCEX. Disponível em: <https://funcex.org.br/\#>.

HADDAD, P. R. Economia regional: teorias e métodos de análise. Fortaleza: [s.n.].

IBRAM. Relatório Anual IBRAM. Brasília: [s.n.]. Disponível em:

<http://portaldamineracao.com.br/ibram/wp-content/uploads/2017/05/2014-2015.pdf>.

MEYER, T. R.; PAULA, L. F. DE. Taxa de Câmbio, Exportações e Balança Comercial no Brasil: Uma Análise do Período 1999-2006. Revista de Análise Econômica, v. 27, n. 51, p. 187-219, 2009.

MONTENEGRO, R. L.; GONÇALVES, E.; ALMEIDA, E. Spatial and temporal dynamics of innovation in the state of são paulo: A review of externalities diversification and specialization. Estudos Economicos, v. 41, n. 4, 2011. 
NAHAS, A. Rio Acima: Fragmentos da história de Minas. Belo Horizonte: [s.n.].

NAHAS, M. M. et al. Especialização e diversificação produtiva: um modelo de painel espacial para a indústria extrativa mineral em Minas Gerais, 2000-2010. Nova Economia, 2019.

REVISTA NEGÓCIOS. Brasil tem exportação recorde de minério em 2016, mas receita recua por preço. 2017, 2017.

RIBEIRO, F. et al. CENÁRIOS PARA O COMÉRCIO EXTERIOR BRASILEIRO (20202021): ESTIMATIVAS DOS IMPACTOS DA CRISE DA COVID-19. Brasília: [s.n.]. Disponível em:

<https://www.ipea.gov.br/portal/images/stories/PDFs/nota_tecnica/200428_nt_dinte_17.pdf>.

ROCHA, A. . Internacionalização das empresas brasileiras. Rio de Janeiro: [s.n.].

RUIZ, F. Exportações brasileiras: Fatores Explicativos da Participação das Micro e Pequenas Empresas. 1a. ed. São Paulo: SENAC, 2007.

SALVATO, M. A.; SANT'ANNA, P. H.; SILVA, L. A. G. DA. Evolução da balança comercial brasileira no período de câmbio flutuante. Revista Economia \& Tecnologia, 2008.

SECEX. Informações sobre a pauta de exportações brasileira. [s.l: s.n.]. Disponível em: <http://www.mdic.gov.br/index.php/legislacao/157-portarias-secex/1360-portarias-dasecretaria-de-comercio-exterior-secex-ano-de-2014>.

SOUZA, I. L. S.; VIEIRA, N. M. COMPETITIVIDADE DAS EXPORTAÇÕES MINEIRAS: UMA ANÁLISE POR NÍVEL DE INTENSIDADE TECNOLÓGICA NO PERÍODO 2001/20141Diamantina: 2016Disponível em:

<https://diamantina.cedeplar.ufmg.br/portal/download/diamantina-2016/106-173-1RV_2016_10_09_00_31_13_626.pdf>

TORRES, G. P.; PALERMO, P. U.; PORTUGAL, M. S. O desempenho da indústria no Rio Grande do Sul (RS), entre 1996 e 2007: uma análise comparada através do método ShiftShare. Indicadores Econômicos FEE, v. 41, n. 1, p. 45-74, 2013.

VAL, V. DA C.; VIANA, V. C. K. R.; MARTINS, L. U. S. De sertão inóspito às Minas do Ouro: nota histórica. Memórias do Judiciário Mineiro. Jurisprudência Mineira, v. 63, n. 201, p. 13-19, 2012.

VALE, A. R.; CALDERARO, R. A. P.; FAGUNDES, F. N. A cafeicultura em Minas Gerais: estudo comparativo entre as regiões Triângulo Mineiro/Alto Paranaíba e Sul/Sudoeste.

Campo-Território: revista de geografia agrária, v. Edição esp, p. 1-23, 2014.

VEJA. Tragédia em Mariana: para que não se repita. Revista Veja, 2015.

\section{NOTAS DE AUTOR}

Nome: Rosa Livia Montenegro- Concepção. Coleta de dados, Análise de dados, Elaboração do manuscrito, Participação ativa da discussão dos resultados; revisão e aprovação da versão final do trabalho

Nome: Sávio Augusto Tavares Costa- Concepção e elaboração do manuscrito. Coleta de dados Revisão e aprovação da versão final do trabalho.

\section{FINANCIAMENTO}

Não se aplica.

\section{CONSENTIMENTO DE USO DE IMAGEM}

Não se aplica

APROVAÇÃO DE COMITÊ DE ÉTICA EM PESQUISA

Não se aplica. 
CONFLITO DE INTERESSES

Os autores declaram que não há conflito de interesses.

\section{LICENÇA DE USO}

Este artigo está licenciado sob a Licença Creative Commons CC-BY-NC. Com essa licença você pode compartilhar, adaptar, criar para qualquer fim, sem uso comercial e desde que atribua a autoria da obra.

\section{HISTÓRICO}

Recebido em: 01-05-2020

Aprovado em: 04-02-2021 